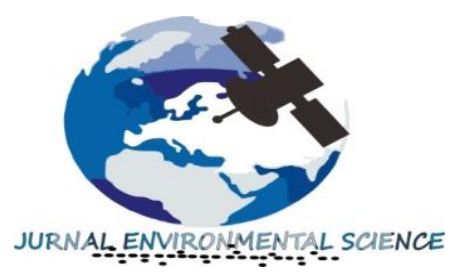

Jurnal Environmental Science

Volume 1 Nomor 1 Oktober 2018.

p-ISSN : 2654-4490 dan e-ISSN : 0000-0000

Homepage at : ojs.unm.ac.id/JES

E-mail:jes@unm.ac.id

\title{
Prediksi Penurunan Muka Tanah Menggunakan Teknik Differential Interferometic Synthetic Aperture Radar (Dinsar) Di Kota Makassar Indonesia
}

\author{
Nurul Afdal Haris \\ Jurusan Geografi, Fakultas Matematika dan Ilmu Pengetahuan Alam, \\ Universitas Negeri Makassar, 2018, Indonesia.
}

\begin{abstract}
Based ont the results of the ALOS Palsar image data analysis using the Differential Interferometric Synthetic Aperture Radar (DInSAR) technique on ENVI Sarscape application. The results of this study indicated that the amount of land subsidence in Makassar City from 2007-2011 was $5.8 \mathrm{~cm}$ with an average rate of land subsidence reaching $0.73 \mathrm{~cm} /$ year. Areas run into land subsidence are all subdistricts in Makassar City with variations land subsidence values from $0.09-5.8 \mathrm{~cm}$.
\end{abstract}

Keywords: ALOS Palsar, DInSAR, Land subsidence, ENVI + Sarscape

\begin{abstract}
ABSTRAK
Berdasarkan hasil analisis data citra ALOS Palsar menggunakan teknik Differential Interferometric Synthetic Aperture Radar (DInSAR) pada aplikasi ENVI Sarscape. Dari 2007-2011 adalah 5,8 cm dengan tingkat rata-rata penurunan tanah mencapai $0,73 \mathrm{~cm} /$ tahun. Wilayah yang mengalami penurunan tanah adalah semua kecamatan di Kota Makassar dengan variasi nilai penurunan tanah dari $0,09-5,8 \mathrm{~cm}$.
\end{abstract}

Kata kunci: ALOS Palsar, DInSAR, Land subsidence, ENVI + Sarscape

\section{PENDAHULUAN}

Penurunan muka tanah (land subsidence) merupakan suatu proses yang didasarkan atas suatu datum tertentu berupa kerangka referensi geodesi terhadap gerakan muka tanah yang didalamnya terdapat berbagai macam variabel penyebabnya (Marfai, 2006). Berdasarkan hasil penelitian tentang penurunan muka tanah sebelumnya, beberapa penyebab terjadinya penurunan muka tanah adalah penurunan karena beban bangunan (Quaxiang .et.al, 2001), pengambilan air tanah yang berlebihan
(Burbey, 2005), serta konsolidasi alamiah lapisan tanah (Wei, 2006).

Kota Makassar yang merupakan sebuah kota yang tengah mengalami perkembangan dan pertumbuhan yang pesat. Semakin banyaknya bangunan tak terkecuali pemukiman akan menyebabkan penggunaan air tanah yang berlebihan yang akan menyebabkan perubahan pada lapisan tanah. Hal ini tidak dapat dipungkiri, jumlah penduduk Kota Makassar pada tahun 2010 mencapai 1,399 juta jiwa, sehingga kebutuhan akan tempat bermukim juga semakin tinggi. Dibandingkan dengan luas kota Makassar 
yang hanya $175,77 \mathrm{~km}^{2}$, berarti kepadatan penduduk di Kota Makassar sebesar 7.960 jiwa $/ \mathrm{km}^{2}$ (Kota Makassar dalam Angka, 2010).

Dalam analisis untuk mengetahui besaran penurunan muka tanah. Perkembangan dalam teknologi telah menemukan ataupun memunculkan beragam cara untuk melaksanakan pemantauan serta pemetaan terhadap aktifitas pergerakan tanah. Salah satu teknologi yang dikembangkan untuk pemantauan penurunan muka tanah adalah dengan menggunakan teknologi Differential Interferometry Synthetic Aperture Radar (DInSAR). DInSAR merupakan teknologi geodesi yang selama ini telah dikembangkan dengan baik beberapa dekade terakhir untuk menunjang terhadap pengamatan penurunan permukaan dengan akurasi yang tinggi dengan ketelitian pada sentimeter. (Geodesi ITB, 2007)

Berdasarkan uraian tersebut, maka dilakukanlah analisis dengan pemanfaatan teknik DInSAR pada muka tanah di Kota Makassar dengan mengangkat judul penelitian "Prediksi Penurunan Muka Tanah Menggunakan Teknik Differential Interferometric Synthetic Aperture Radar (DInSAR) di Kota Makassar Indonesia".

\section{METODE PENELITIAN}

\section{a. Jenis dan Lokasi Penelitian}

Jenis penelitian berdasarkan bidang yang diteliti adalah penelitian kuantitatif dengan analisis deskriptif data sekunder berbasis spasial. Penelitian dilaksanakan di Kota Makassar. Adapun variabel pada penelitian ini terdiri dari; (1) Beda Fase pada Citra ALOS PALSAR L1.1 20072011, dan (2) Topografi Kota Makassar.

\section{b. Teknik Pengumpulan dan Analisis Data}

Data yang digunakan dalam penelitian ini adalah Citra ALOS Palsar L1.1 FBS 2007-2011 dan Citra DEM SRTM3 v2. Citra ALOS PALSAR L1.1 sebagai citra utama yang digunakan dalam analisis ini dapat di peroleh di https://vertex.daac.asf.alaska.edul.

Sedangkan alat yang digunakan dalam analisis data adalah Laptop Asus X450J, aplikasi Envi 5.3 + Sarscape 5.2, ArcGIS 10.5, ASF Map Ready, Microsoft Office 2016.

Penentuan besar laju penurunan muka tanah dilakukan dengan menentukan titik sampel berdasarkan pada sistem grid. Jumlah sampel yang ditentukan dalam penelitian ini adalah sebanyak 20 titik sampel. Adapun kenampakan dari penempatan titik sampel ditunjukkan pada gambar berikut,

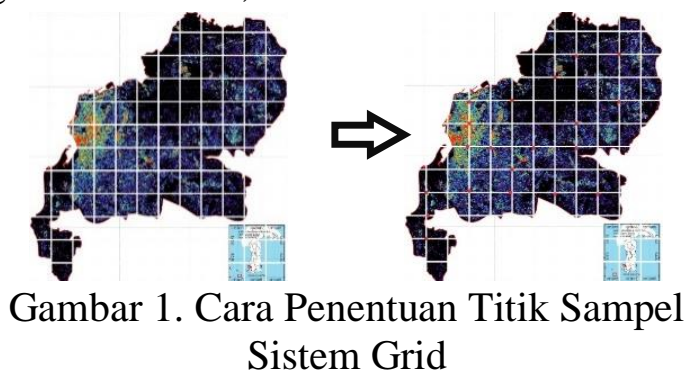

Dari 20 data besar penurunan muka tanah yang diperoleh dari 20 titik sampel, kemudian dirata-ratakan untuk mendapatakan nilai besar laju penurunan muka tanah per tahunnya

Analisis dengan teknik DInSAR dapat dilihat diagram alir dibawah ini,

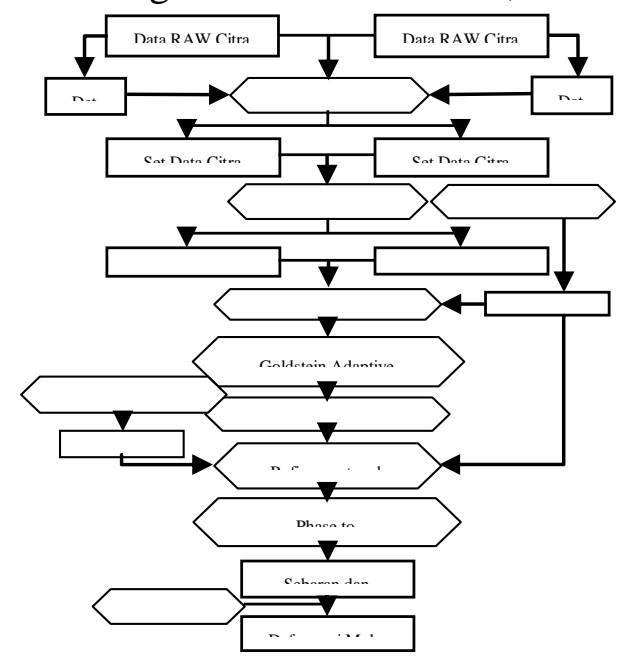


Gambar 2. Diagram Alir Analisis Citra Metode DInSAR

\section{HASIL}

1. Besar Penurunan Muka Tanah

Hasil analisis citra dengan teknik DInSAR yang dilakukan pada 4 pasang citra dapat dilihat pada gambar berikut,

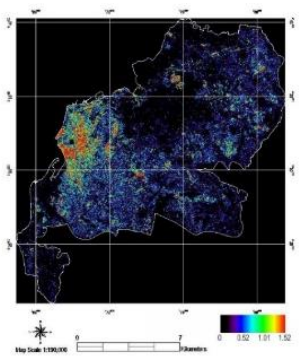

(a)

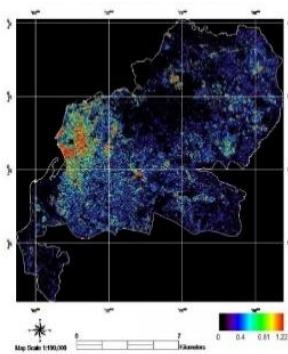

(c)

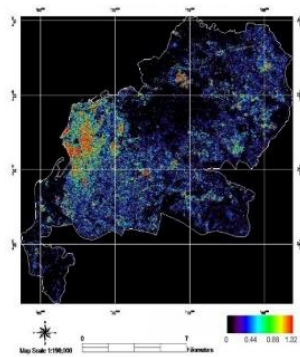

(b)

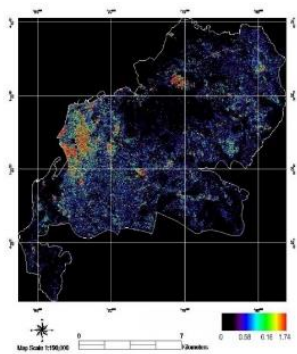

(d)
Gambar 3. Peta Penurunan Muka Tanah Kota Makassar (a) 2007-2008, (b) 2008-2009, (c) 2009-

$$
\text { 2010, (d) 2010-2011 }
$$

Dari gambar tersebut dapat diuraikan besar penurunan muka tanah di Kota Makassar pada tabel berikut ini,

Tabel 1 Besar Penurunan Muka Tanah Kota Makassar

\begin{tabular}{ccc}
\hline \multirow{2}{*}{ TAHUN } & \multicolumn{2}{c}{ Penurunan $(\mathbf{c m})$} \\
\cline { 2 - 3 } & Minimum & Maksimum \\
\hline $2007-$ & 0,10 & 1,52 \\
2008 & & 1,32 \\
$2008-$ & & \\
2009 & 0,11 & 1,22 \\
$2009-$ & & \\
2010 & 0,09 & 1,74 \\
$2010-$ & & \\
2011 & 0,12 & 5,8 \\
$2007-$ & & \\
2011 & 0,09 &
\end{tabular}

Sumber: Hasil Analisis Citra, 2018

\section{Laju Penurunan Muka Tanah}

Penentuan 20 titik sampel dengan sistem grid dalam analisis data laju penurunan muka tanah, maka diperoleh nilai laju penurunan muka tanah seperti pada gambar berikut,

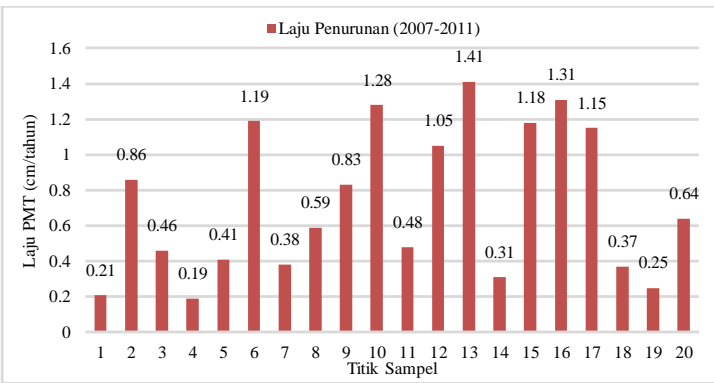

Gambar 4. Grafik Besar Laju Penurunan Muka Tanah Kota Makassar Tahun 20072011

Dari gambar tersebut maka diperoleh nilai laju penurunan muka tanah di Kota Makassar sebesar 0,73 cm/tahun.

3. Wilayah yang Mengalami Penurunan Muka Tanah

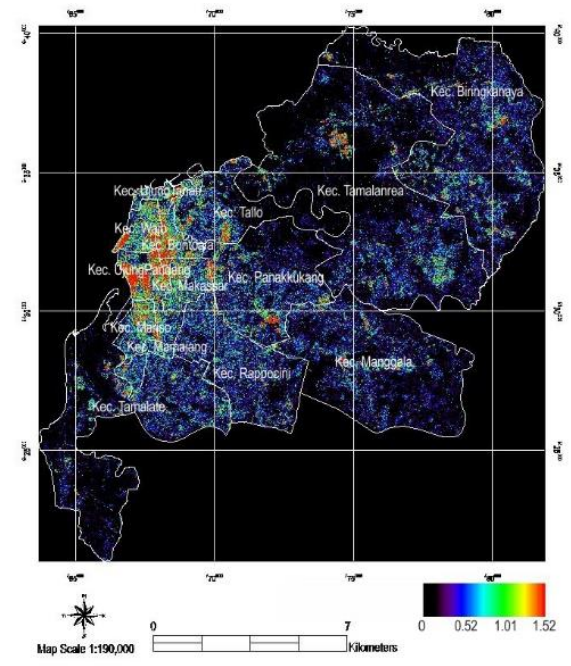

Gambar 5. Peta Wilayah Kota Makassar yang Mengalami Penurunan Muka Tanah Tahun 2007-2011

Secara administratif Kota Makassar yang memiliki 14 kecamatan, berdasarkan analisis yang dilakukan maka dapat diketahui bahwa seluruh kecamatan yang 
ada di Kota Makassar mengalami penurunan muka tanah.

\section{PEMBAHASAN}

Besar penurunan muka tanah di Kota Makassar sesuai dengan hasil analisis yang disajikan pada Tabel 1, bahwa pada tahun 2007-2008 mencapai $1,52 \mathrm{~cm}$. Pada tahun 2008-2009 besar penurunan muka tanah mencapai 1,32 cm. Pada tahun 2009-2010 besar penurunan muka tanah mencapai 1,22 cm. Pada tahun 2010-2011 besar penurunan muka tanah mencapai $1,74 \mathrm{~cm}$.

Begitupun pada Gambar 4 dapat diketahui laju penurunan muka tanah terkecil adalah $0,19 \mathrm{~cm} /$ tahun yang ditemukan pada titik 4 yang berada pada Kecamatan Tamalate. Dan laju penurunan muka tanah terbesar adalah $1,31 \mathrm{~cm} /$ tahun yang ditemukan pada titik 16 yang berada pada Kecamatan Bontoala. Jumlah laju penurunan muka tanah yang terjadi di Kota Makassar berdasarkan 20 titik sampel yang telah ditentukan adalah sebesar 14,53 $\mathrm{cm} /$ tahun/20titik dengan rata-rata penurunan muka tanah adalah sebesar 0,73 $\mathrm{cm} /$ tahun.

Berdasarkan pada Tabel 1 tentang data penurunan muka tanah di Kota Makassar yang dibagi berdasarkan kecamatan maka dapat diketahui bahwa seluruh kecamatan yang ada di Kota Makassar mengalami penurunan muka tanah. Kecamatan yang mengalami penurunan muka tanah terendah dari nilai penurunan muka tanah yang paling besar adalah Kecamatan Tallo dengan nilai penurunan muka tanah sebesar $5,31 \mathrm{~cm}$ dalam rentang waktu tahun 2007 hingga tahun 2011. Adapun Kecamatan Ujung Pandang adalah daerah yang mengalami penurunan muka tanah terbesar dengan nilai penurunan muka tanah sebesar $5,83 \mathrm{~cm}$ dalam rentang waktu tahun 2007 hingga tahun 2011.
Penurunan muka tanah yang terjadi di Kota Makassar disebabkan oleh karena adanya beban bangunan. Hal ini sesuai dengan hasil penelitian Quaxiang, et.al pada tahun 2001 dan teori oleh Sutanto pada tahun 2005 bahwa beban bangunan sangat berpengaruh terhadap terjadinya penurunan muka tanah. Begitupun dengan laju penurunan muka tanah yang terjadi secara berkala tidak lepas dari pengaruh penggunaan air pada setiap bangunan yang ada di Kota Makassar, hal ini sesuai dengan hasil penelitian oleh Burbey pada tahun 2005. Begitupula dengan keadaan geologi Kota Makassar yang masih terbilang muda, berdasarkan kutipan pada penelitian Alfian Budi, et.al di Kota Semarang tahun 2016, jenis tanah yang masih muda masih mengalami proses konsolidasi dan kompaksi, hal ini dapat mengakibatkan terjadinya penurunan muka tanah.

\section{KESIMPULAN}

Dapat disimpulkan dari hasil analisis, nilai besaran penurunan muka tanah Kota Makassar dalam rentang waktu tahun 2007 hingga tahun 2011 adalah 0,09-5,8 cm dengan laju Penurunan muka tanah Kota Makassar dalam rentang waktu tahun 2007 hingga tahun 2011 mencapai 0,73 $\mathrm{cm} /$ tahun. Dimana seluruh Kecamatan yang ada di Kota Makassar mengalami penurunan muka tanah yaitu sebanyak 14 kecamatan se Kota Makassar.

\section{SARAN}

1. Pada penelitian selanjutnya, sebaiknya kajian tidak hanya sampai pada pencarian besar penurunan muka tanah. Kajian bisa dilanjutkan hingga menganalisis faktor-faktor dari penurunan muka tanah yang terjadi. Serta dampak yang disebabkan karena 
terjadinya penurunan muka tanah tersebut.

2. Perlu dilakukannya kajian DInSAR dengan menggunakan citra satelit yang berbeda pada daerah Kota Makassar sehingga dapat dibandingkan seberapa akurat citra ALOS Palsar dibandingkan dengan citra satelit lainnya.

3. Selain membandingkan dengan citra satelit yang lain. Penggunaan software atau aplikasi lain juga akan berkontribusi untuk membandingkan yang manakah aplikasi yang baik digunakan untuk citra satelit tertentu dalam analisis ini.

\section{DAFTAR PUSTAKA}

BPS Kota Makassar. 2010. Pertumbuhan dan Persebaran Penduduk. Pemkot Makassar.

Budi, Alfian, Darmo Bambang, Awaluddin. 2016. Pemantauan Penurunan Muka Tanah Kota Semarang Tahun 2016 Menggunakan Perangkat Lunak GAMIT 10.6. Teknik Geodesi Fakultas Teknik, Universitas Diponegoro: Semarang.

Burbey, T.J., 2005. Use of vertical and horizontal deformation data with inverse models to quantify parameters during aquifer testing. Land Subsidence: Proceedings of the 7th International Symposium on Land Subsidence: Shanghai, Shanghai Scientific \& Technical Publishers 560-569.

Geodesi ITB. 2007. Teknologi InSAR (Interferometric Synthetic Aperture Radar). Kelompok Keahlian Geodesi ITB: Bandung.
Marfai MA, and King, L. 2006. Impact of the escalated tidal inundation due to land subsidence in a coastal environment. Nat Hazards (2008) 44:93-109.

Quaxiang L., Ding X., Chen Y., Li Z., dan Li Z. 2001. Ground Settlement of Chek Lap Kok Airport, Hongkong, detected by Satellite Synthetic Aperture Radar Interferometry. The International Archieves of The Photogrammetry, Remote Sensing and Spatial Information Sciences, New York, 331-339.

Sutanto, Rachman. 2005. Dasar-Dasar Ilmu Tanah, Konsep dan Kenyataan. Kanisius: Yogyakarta.

Wei, Q. 2006. Land Subsidence and Water Management in Shanghai. Master's Thesis. Department of Land and Water Resources Management. TU Delft, The Netherlands, May 2006, $65 \mathrm{pp}$. 
